\title{
Metabolic fingerprinting of root, stem and leaf extracts of Phyllanthus amarus
}

\author{
S. S. Sravanthi Pammi, T. V. S. Padmavathi, Archana Giri*
}

Centre for Biotechnology, Institute of Science and Technology, Jawaharlal Nehru Technological University, Kukatpally, Hyderabad, Telangana, India

Received: 18.02.2016

Accepted: 27.03 .2016

Published: 08.04.2016

*Address for correspondence:

Archana Giri, Centre

for Biotechnology,

Institute of Science and

Technology, Jawaharlal

Nehru Technological

University, Kukatpally,

Hyderabad - 500 085,

Telangana, India.

E-mail: archanagirin@yahoo.

co.in

\begin{abstract}
Phyllanthus amarus belonging to family Euphorbiaceae is an important medicinal plant from ancient times which is used in Chinese and Ayurvedic medicine. It is a small annual herb mostly found in Central and Southern India. All parts of this plant have medicinal value and are used in traditional medicines for curing various diseases such as jaundice, hepatitis B, C, microbial infections, viral diseases, tumors, and kidney stones. Keeping in view its immense medicinal potential, phytochemical analysis was performed using different solvents such as ethyl acetate, dimethylformamide, chloroform, dichloromethane, and n-Hexane. All the plant parts, viz., root, stem and leaf were separately analyzed for the detection of phenols and flavonoids, of which leaf exhibited the highest concentration compared to root and stem. Maximum percentage of phenols and flavonoids could be detected with dimethylformamide in comparison to other solvents that were used in the study. Dimethylformamide leaf extract displayed highest phenolic content of $40.75 \mathrm{mg} / \mathrm{g}$ and the highest flavonoid content of $51.5 \mathrm{mg} / \mathrm{g}$.
\end{abstract}

KEY WORDS: Flavonoids, phenols, Phyllanthus amarus, phytochemical

\section{INTRODUCTION}

India is one of the richest biodiversity centers in the world with different types of plant species. This huge diversity is due to different agro-climatic conditions throughout. Every higher plant species has got its own metabolic fingerprint with secondary metabolites of pharmaceutical value, which is used in traditional and modern medicines. Herbal products are safe to human and environment in contrast to the synthetic drugs (Panda et al., 2012). In India, plant drug contribution is as much as $80 \%$ compared to developed countries (Babu et al., 2011). Traditional systems of medicine are widely practiced due to high population, high treatment cost, side effects of synthetic drugs, insufficient drug supply, and development of resistance to synthetic drugs. In the recent past, the herbal system of medicines has reached a very vital phase. Green plants are used as raw materials as they possess a variety of compounds, which can be extracted and can be used for a variety of scientific investigations. Secondary metabolites present in plant are commercially important in pharmaceutical industries (Joy et al., 2001).

Phyllanthus amarus, commonly called as Bhui Amla, belonging to family Euphorbiaceae, is a small herb in southern India with great medicinal value (Nair and Abraham, 2008), growing to a height of $50-70 \mathrm{~cm}$, bearing herbaceous branches with smooth and light green bark. It has numerous pale green flowers and the fruits are tiny, smooth capsules containing seeds. P. amarus root and leaf extract showed significant inhibition of hepatitis $C$ virus (Ravikumar et al., 2011). Leaves, roots, stem, bark and berries of this genus contain lignans (e.g. phyllanthin and hypophyllanthin) and a variety of other phytochemicals such as alkaloids, flavonoids (e.g. quercetin), glycosides, ellagitannins, and phenylpropanoids (Bagalkotkar et al., 2006). Common lipids, sterols, and flavonols also occur in the plant which makes it an unusual choice for innovating phytopharmaceuticals. The objective of this study is to analyze and quantify phenols and flavonoids in different parts of $P$. amarus (root, stem and leaf) using different solvents.

\section{MATERIALS AND METHODS}

\section{Collection of Plant Material}

Plants of P.amarus were collected from fields of Andhra Pradesh, India, and authenticated by Dr. S. B. Padal, Associate Professor, Department of Botany, Andhra University. 


\section{Sample Preparation}

Fresh plant material was washed under running tap water and separated into three different parts, i.e., stem, root and leaves. They were dried under shade to remove moisture and homogenized to fine powder and stored in air tight bottles. The solvents used for the extraction were ethyl acetate, dimethylformamide, dichloromethane, chloroform, and n-Hexane.

About $1 \mathrm{~g}$ powder of all plant parts (root, stem, leaves) was weighed separately and ground well. Dried powder was extracted in different solvents in a conical flask and kept on a rotary shaker at 190-220 rpm for $24 \mathrm{~h}$. The filtrates were concentrated under reduced pressure using a Rota Vapor (IKA, Germany).

\section{Phytochemical Screening}

The preliminary phytochemical tests on different extracts were performed by specific reagents using standard phytochemical methods.

\section{Estimation of Total Phenolic Content}

Total phenolic content was estimated by the procedure of Singleton and Rossi (1965) and McDonald et al. (2001).

\section{Preparation of Standard Solution}

Tannic acid was used as standard for estimating the total phenolic content in P. amarus $(0.1 \mathrm{mg}$ of tannic acid was taken in $1 \mathrm{ml}$ of methanol to get $0.1 \mathrm{mg} / \mathrm{ml}$ standard solution).

\section{Preparation of Calibration Curve}

Folin-Ciocalteu reagent method was used for the determination of phenolic content in plant extracts using spectrophotometric analysis (Singleton and Rossi, 1965; McDonald et al. 2001). Different aliquots of tannic acid $(50,100,150,200$, and $250 \mu \mathrm{l})$ were taken from the stock solution $(0.1 \mathrm{mg} / \mathrm{ml})$ in test tubes. To that $5 \mathrm{ml}$ of Folinciocalteu reagent was added and mixed well. Later $4 \mathrm{ml}$ of sodium carbonate was added and all the test tubes were vortexed for $50 \mathrm{~s}$. All the test tubes were kept for $30 \mathrm{~min}$ in water bath at $40^{\circ} \mathrm{C}$. Total phenolic content in the plant extract was estimated using different aliquots of tannic acid as standard. The color developed was measured at $680 \mathrm{~nm}$ using UV-VIS spectrophotometer (Elico, India). Blank was prepared with Folin-Ciocalteu reagent and sodium carbonate without plant extract or tannic acid. A graph was plotted by taking the optical density values on Y-axis and concentration of tannic acid on X-axis (Figure 1).

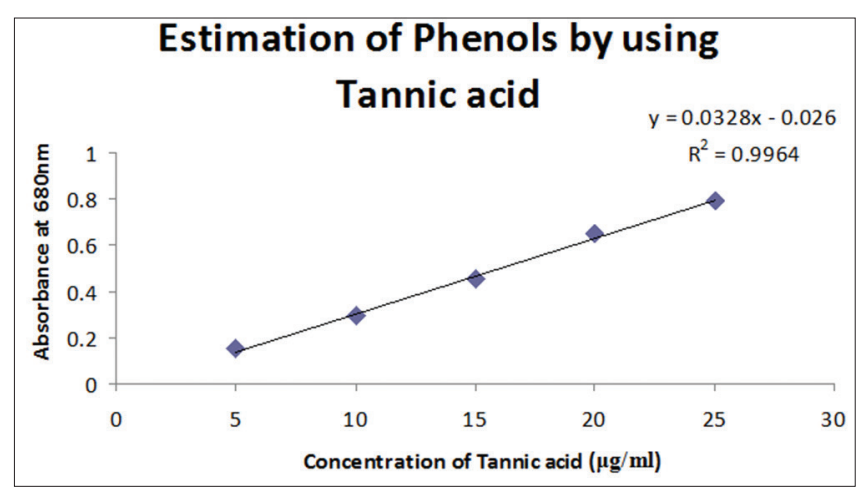

Figure 1: Standard graph for tannic acid

\section{Preparation of Test Sample Solution}

To $1 \mathrm{ml}$ of the plant extract, $5 \mathrm{ml}$ of FC reagent and $4 \mathrm{ml}$ $\mathrm{Na}_{2} \mathrm{CO}_{3}$ were added and incubated for $30 \mathrm{~min}$ at $40^{\circ} \mathrm{C}$. OD values were taken at $680 \mathrm{~nm}$. Quantification of phenols was done for root, stem and leaf extracts of $P$. amarus based on the absorbance measured and by comparing the results with a standard curve of tannic acid. Phenol concentration was estimated from the standard curve in root, stem and leaf extracts separately and was expressed in terms of tannic acid (mg of tannic acid/g of extract).

\section{Estimation of Total Flavonoid Content}

Total flavonoid content was estimated by the procedure of Satishkumar et al., 2008; Patel et al., 2010; Patel et al., 2012; Pallab et al., 2013.

\section{Preparation of Standard Solution}

Quercetin was used as standard for estimating the total flavonoid content of the plant P. amarus (1 $\mathrm{mg}$ of quercetin was dissolved in $1 \mathrm{ml}$ of methanol and was taken as standard to get $1 \mathrm{mg} / \mathrm{ml}$ solution).

\section{Preparation of Calibration Curve}

Quercetin method was used for the determination of total flavonoid content in plant extracts using spectrophotometric analysis (Satishkumar et al., 2008; Patel et al., 2010; Patel et al., 2012; Pallab et al., 2013). Different aliquots of quercetin $(15,30,60,90,120,150$, 180 , and $210 \mu \mathrm{l})$ were taken from the stock solution $(1 \mathrm{mg} / \mathrm{ml})$ in test-tubes. To those respective dilutions of methanol was added and made the volume up to $1500 \mu \mathrm{l}$ and mixed well. Later $0.1 \mathrm{ml}$ of $2 \%$ aluminum chloride and $0.1 \mathrm{ml}$ of $1 \mathrm{M}$ potassium acetate was added and mixed well. All the test-tubes were allowed to stand for $30 \mathrm{~min}$ at room temperature. Blank was prepared with aluminum chloride and potassium acetate without plant extract or quercetin. Absorbance was measured for the color that was 
developed at $420 \mathrm{~nm}$ using UV-VIS spectrophotometer. A graph was plotted by taking the optical density values on Y-axis and concentration of quercetin on X-axis (Figure 2).

\section{Preparation of Test Sample Solution}

To $1 \mathrm{ml}$ of the plant extract, $0.5 \mathrm{ml}$ of $\mathrm{AlCl}_{3}$ was added to the plant extract and incubated for $1 \mathrm{~h}$ at room temperature. To that $0.1 \mathrm{ml}$ of potassium acetate $\left(\mathrm{CH}_{3} \mathrm{COOK}\right)$ was added and mixed well. Quantification of flavonoids in root, stem and leaf extracts of $P$. amarus was done based on the absorbance measured at $420 \mathrm{~nm}$ and by comparing the results with standard curve of quercetin. Flavonoid concentration was estimated from the standard curve in root, stem and leaf extracts separately and was expressed in terms of quercetin ( $\mathrm{mg}$ of quercetin/g of extract).

\section{Calculation}

Test concentration $=$ OD of Test/Dilution Factor.

Dilution Factor $=$ OD of Standard/Concentration of Standard.

\section{RESULTS AND DISCUSSION}

Phenols and flavonoids in different parts (root, stem and leaf) of $P$. amarus were evaluated in different solvents, i.e., ethyl acetate, dimethylformamide, chloroform, dichloromethane and n-Hexane (Shah and Yadav, 2015). Leaf was found to possess the highest activity of phenols and flavonoids compared to root and stem. Dimethylformamide was found to be the best solvent for extraction of phenols and flavonoids in root, stem and leaf extracts among the solvents tested. Dimethylformamide leaf extract exhibited highest phenol percentage of $46.77 \%$ (Figure 3) and highest flavonoid percentage of 56.18\% (Figure 4).

There was report on qualitative and quantitative phytochemical screening of different plant parts of $P$. amarus with water, methanol, ethyl acetate and petroleum ether (Awasthi et al., 2015). Similar studies have been reported in Phyllanthus fraternus (Kavit et al., 2013) and different species of Phyllanthus leaf extracts for preliminary phytochemical evaluation (Gopinath et al., 2012).

Gas chromatography-mass spectrometry (GC-MS) analysis of $P$. amarus in dimethylformamide leaf extract revealed the presence of compounds displayed in Table 1 (Figure 5). Carissanol dimethyl ether and fumaric acid were detected in maximum concentration by GC-MS analysis. Fumaric acid has been reported to possess exceptional anti-

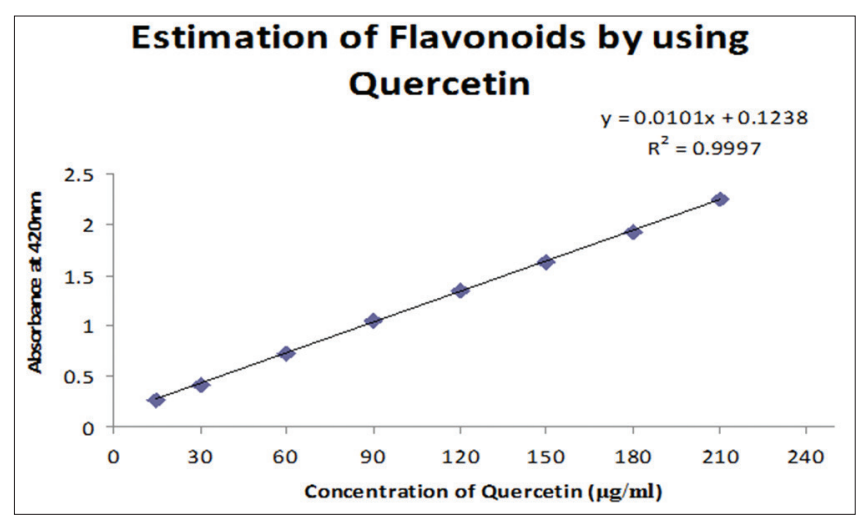

Figure 2: Standard graph for quercetin

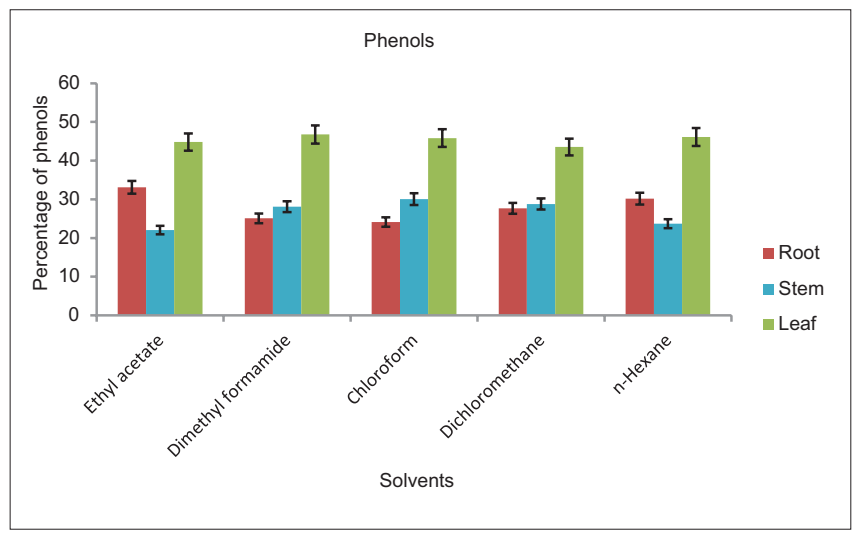

Figure 3: Comparative study of phenols in different parts of Phyllanthus amarus using different solvents

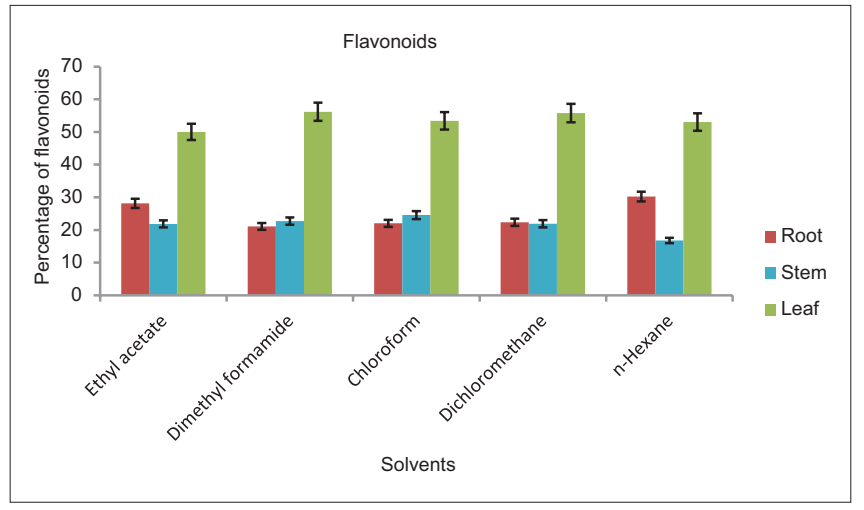

Figure 4: Comparative study of flavonoids in different parts of Phyllanthus amarus using different solvents

microbial and antioxidant properties. Hence, it was mostly used in a number of industrial processes (Huan et al., 2002). Our reports are in corroboration with the reports of Veena Gayathri in Tridax procumbens (Krishnaswamy and Christina, 2015) and Dib et al., (2013) in Arbutus unedo. Sylvatesmin detected in this extract was reported to have high radical scavenging activity (Saha et al., 2015) and the compound 1-Heptacosanol was reported to have antimicrobial, anti-oxidant and nematicidal properties in some 


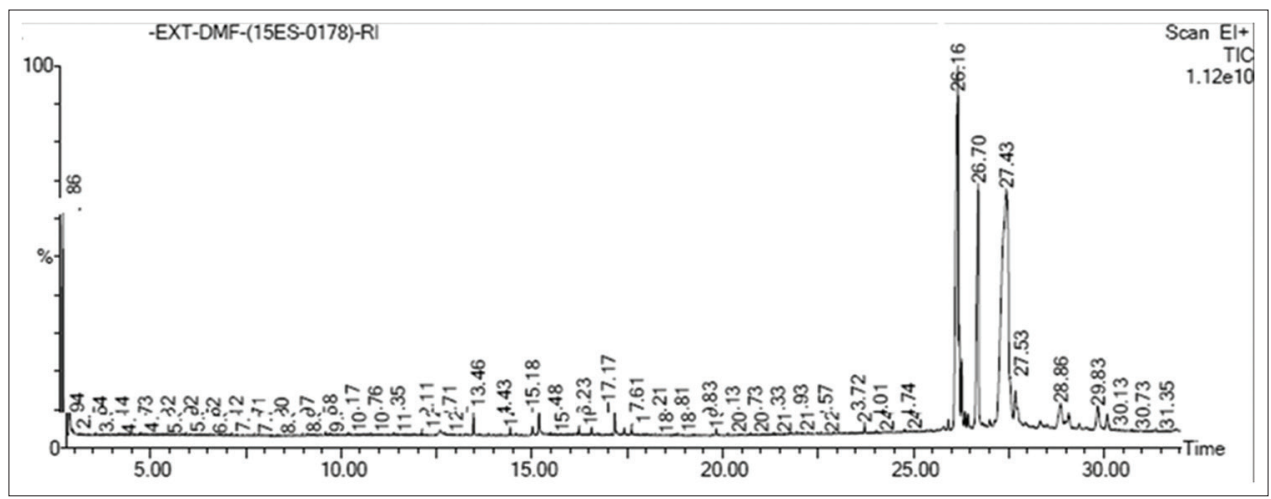

Figure 5: Gas chromatography-mass spectrometry chromatogram of dimethyl formamide leaf extract of Phyllanthus amarus

Table 1: List of compounds detected by GC-MS analysis in Phyllanthus amarus dimethylformamide leaf extracts

\begin{tabular}{llc}
\hline Rt (min) & Compound name & CAS \\
\hline 2.863 & Formamide, N,N-Dimethyl- & $68-12-2$ \\
26.163 & Carissanol dimethyl ether & $41328-80-7$ \\
26.203 & No library & \\
26.273 & No library & \\
26.703 & No library & $487-39-8$ \\
27.434 & Sylvatesmin & $900344-90-4$ \\
27.674 & Fumaric acid, 2-isopropylphenyl & \\
& pentadecyl ester & $23693-18-7$ \\
28.869 & Phenethylamine, 2-methoxy-. & \\
& alpha.-methyl-4,5-(methylenedioxy)- \\
29.845 & 1-Heptacosanol & $2004-39-9$ \\
\hline
\end{tabular}

GC-MS: Gas chromatography-mass spectrometry, RT: Retention time

marine algae (Murugan and Iyer, 2014). Methoxy group containing compounds have been reported to exhibit antimicrobial action by distorting cell surface (Baluja et al., 2015). GC-MS analysis of our present study also revealed the presence of methylenedioxy compound which could be liable for anti-microbial activity.

\section{CONCLUSION}

Medicinal and aromatic plants comprise the basis of primary health care for bulk of the population and are an important source of income for rural population. Ancient traditional systems of medicine are practiced in Asia mainly because of historical circumstances and cultural beliefs. Medicinal plants are accessible, affordable and culturally appropriate source of primary health care for more than $80 \%$ of the Asian population according to the World Health Organization. There is a need for harmonization among various institutes of the region working on medicinal plants and traditional medicines to develop drugs for health care (Swami et al., 2006). The whole plant of P. amarus was best suitable for herbal medicine because of many active constituents present in it and opens a gate way for novel drug discovery.

\section{REFERENCES}

Awasthi A, Singh R, Agrawal MK. Qualitative and quantitative phytochemical screening of different plant parts of Phyllanthus amarus Schum. and Thonn. collected from central India with respect to the traditional claims for their medicinal uses. Int J Pharm Sci Res 2015;6:393-8.

Babu NC, Naidu MT, Venkaiah M. Ethnomedicinal plants used by the tribals of Vizianagaram district, Andhra Pradesh. Ann Pharm Pharm Sci 2011;2:1-4.

Bagalkotkar G, Sagineedu SR, Saad MS, Stanslas J. Phytochemicals from Phyllanthus niruri Linn. and their pharmacological properties: A review. J Pharm Pharmacol 2006;58:1559-70.

Baluja S, Chanda S, Nandha K. Antimicrobial activity of some pyrimidine derivatives in DMF and DMSO. Int Lett Chem Phys Astron 2015;56:131-41.

Dib ME, Allali H, Bendiabdellah A, Meliani N, Tabti B. Antimicrobial activity and phytochemical screening of Arbutus unedo L.J Saudi Chem Soc 2013;17:381-5.

Gopinath SM, Rakesh CK, Murthy TP, Dayananda KS. Preliminary phytochemical evaluation of leaf extracts of Gymnema sylvestre, Phyllanthus amarus, Phyllanthus reticulatus of Siddarabetta, Tumkur district, Karnataka. Int J Pharmacogn Phytochem Res 2012;3:109-11.

Huan WY, Ru YZ, Wei ZH. Antioxidant and antimicrobial activity of fumaric acid Alkyl 3-PG ester. J South China Univ Technol (Nat Sci) 2002;202:3.

Joy PP,Thomas J, Mathew S, Skaria BP. Medicinal Plants -Tropical Horticulture. Vol. 2. Calcutta: Naya Prokash; 2001. p. 449-632.

Kavit M, Patel BN, Jain BK. Phytochemical analysis of leaf extract of Phyllanthus fraternus. Res J Rec Sci 2013;2:12-5.

KrishnaswamyVG, Christina. Antibacterial activity of different parts of Tridax procumbens against human pathogens. Int J Curr Res Acad Rev 2015;3:211-8.

McDonald S, Prenzler PD, Autolovich M, Robards K. Phenolic content and antioxidant activity of olive extracts. Food 
Chem 2001;73:73-84.

Murugan K, Iyer VV. Antioxidant activity and gas chromatographic-mass spectrometric analysis of extracts of the marine algae, Caulerpa peltata and Padina gymnospora . Indian J Pharm Sci 2014;76:548-52.

Nair RR, Abraham RS. Integrating the science of pharmacology and bio-informatics of Phyllanthus the wonder plant. Adv Biotech 2008;6:28-30.

Pallab K, Tapan B, Tapas P, Ramen K. Estimation of total flavonoids content (TPC) and antioxidant activities of methanolic whole plant extract of Biophytum sensitivum Linn. J Drug Deliv Ther 2013;3:33-7.

Panda D, Dash SK, Dash GK. Phytochemical examination and antimicrobial activity of various solvent extracts and the selected isolated compounds from roots of Tragia involucrata Linn. Int J Pharm Sci Drug Res 2012;4:44-8.

Patel A, Patel A, Patel A, Patel NM. Estimation of flavonoid, polyphenolic content and in vitro antioxidant capacity of leaves of Tephrosia purpurea Linn. (Leguminosae). Int J Pharm Sci Res 2010;1:66-77.

Patel S, Patel J, Patel RK. To study proximate analysis and biological evaluation of Triphala Guggulu formulation. Int J Pharm Sci Res 2012;4:1520-6.
Ravikumar YS, Ray U, Nandhitha M, Perween A, Naika RH, Khanna N. Inhibition of hepatitis $\mathrm{C}$ virus replication by herbal extract: Phyllanthus amarus as potent natural source, science direct. Virus Res 2011;158:89-97.

Satishkumar T, Baskar R, Shanmugam S, Rajasekaran P, Sadasivam S, Manikandan V. Optimization of flavonoids extraction from the leaves of Tabernaemontana heyneana Wall. Using L16 ortho design. Nat Sci 2008;6:10-21.

Saha H, Srikkanth A, Sikchi S, Rajeswari VD. Comparative evaluation of antimicrobial and anti-inflammatory activities of Ocimum sanctum, Phyllanthus niruri and Cadaba fruticosa: An in vitro approach with emphasis on detection of their bioactive compounds using GC-MS. Int J Biol Chem 2015;9:235-48.

Shah RK, Yadav RN. Qualitative phytochemical analysis and estimation of total phenols and flavonoids in leaf extract of Sarcochlamys pulcherrima Wedd. Glob J Biosci Bio-Technol 2015;4:81-4.

Singleton VL, Rossi JA. Colorimetry of total phenolics with phosphomolybdic-phosphotungstic acid reagents. Am J Enol Vitic 1965;16:144-58.

Swami HS, Dutt RD, Karan V. Compendium of Medicinal and Aromatic Plants - Asia. Vol. 2. Trieste, Italy: ICS-UNIDO; 2006. p. 411. 